\title{
Economic Aspects of Decision Making in Production Processes with Uncertain Component Quality
}

\author{
Tamas Banyai \\ University of Miskolc \\ Egyetemvaros, H-3515, Miskolc, Hungary \\ E-mail.alttamas@uni-miskolc.hu \\ cross $^{\text {ref }}$ http://dx.doi.org/10.5755/j01.ee.30.1.19324
}

\begin{abstract}
Production and service processes always introduce discrepancies between real and expected parameters. Accurate modelling of uncertainties in manufacturing processes has great impact on logistics related factors. In this representation, instead of a deterministic analysis of manufacturing processes with uncertain quality of components, decision making is described with stochastic decision trees. The objective of this work is to show how to include the uncertain quality of components into the optimization of manufacturing processes. This paper proposes a new decision tree model with stochastic parameters that can determine the optimal operations depending on the quality of components to be assembled. After a careful literature review, this paper introduces a model to formulate the problem of decision making in manufacturing and assembly processes depending on the quality of produced batches of components. The model seeks the optimal pre-assembly operation, like testing or repairing while taking into account specific costs, prior and posterior probabilities and likelihoods. Next, we demonstrate an enhanced stochastic decision tree with cumulative hypergeometric probability distributions to find the minimum of expected cost based objective function. Numerical results demonstrate how the proposed model supports the decision making process and increase the efficiency, flexibility and reliability of the manufacturing process.
\end{abstract}

Keywords: Specific Decision Tree; Expected Cost; Manufacturing; Quality Control; Uncertainties.

\section{Introduction}

Decision-making of manufacturing processes becomes more and more complex, because of the globalization of economy and market demands. New opportunities, issues and concepts are introduced. The design and operation of manufacturing processes includes four functional levels, like purchasing, production, distribution and inverse processes. In today's economy, the pressure is on to make the manufacturing processes more and more efficient from the point of view of all of these functional levels. The competition is characterized as competition for customers through the quality, price and availability of products. The quality and price of final products depend on the quality of components. The quality can be described as an uncertain parameter which influences the optimal manufacturing strategy. Quality can be controlled and tested. Within the frame of this research work a new approach is described to support the decision making in manufacturing processes to find the best sampling/reworking process of components with uncertain quality. This research work is based on the idea of Winston's decision tree model (Winston, 1994), which demonstrated the Bayes rule in decision making processes with simple probability values of sampling results.

There are numerous articles related to determining the optimal decisions in manufacturing processes. To build a link between literatures and this research work, we are focusing on the previous research results to answer the following questions: Who is doing what? Who has done what? Who first did it or published it? What are research gaps? Our methodology of structured literature review includes four main steps (Lage \& Filho, 2010):
- $\quad$ search for articles in databases and other sources, like Scopus, Science Direct, Web of Science,

- reduce the number of articles by reading the abstract and identify the main topic,

- define a methodology to analyze the chosen articles,

- describe the main scientific results and identify the scientific gaps and bottlenecks.

Firstly, the relevant terms were defined. It is a crucial phase of the review because there are excellent review articles in the field of manufacturing optimization and we didn't want to produce an almost similar review, but we applied the presented methodology (Banyai et al., 2018). We used the following keywords to search in the Scopus database: "uncertainties" AND "manufacturing" AND "quality" AND "decision tree". Initially, 280 articles were identified. This list was reduced to 150 articles selecting journal articles only. Our search was conducted in September 2017; therefore, new articles may have been published since then.

In the following step, the 150 articles were reduced after reading the abstracts. We excluded articles that did not draw our interest and did not address the economic aspects of decision making in production processes with uncertain component quality. After this reduction, we got 49 articles. We added 4 other articles selected through separate search (Aghdaie et al., 2013; Korponai et al., 2017; Banyaine Toth et al., 2017; Drejeriene \& Drejeris, 2017), so the final list for classification and evaluation from the point of view of scientific results includes 53 articles.

The final list of articles can be classified depending on the subject area. Figure 1 demonstrates the classification of these 37 articles considering ten subject areas. This 
classification shows that the majority of articles are in the fields of engineering, business and management, computer sciences and decision science.

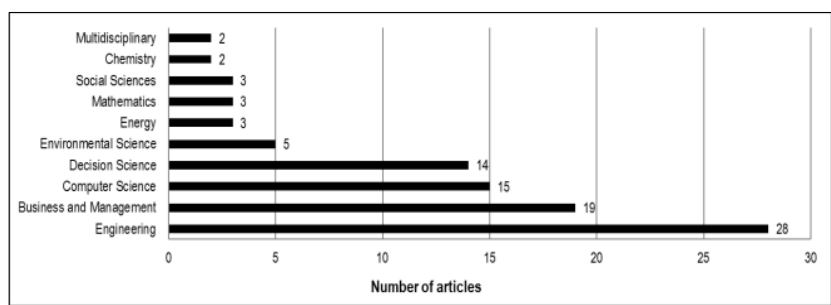

Figure 1. Classification of Articles Considering Subject Areas Based on the Search in Scopus Database

As Figure 2 demonstrates, the support of decision making in manufacturing processes has been researched in the past years. The first article in this field was published in 1995 in the field of operational management (Mehrez et al., 1995) and it was focusing on Petri-net based modelling and support of decision making problems in the field of operational management. The number of published papers has increased in the last 10 years; it shows the importance of this research field.

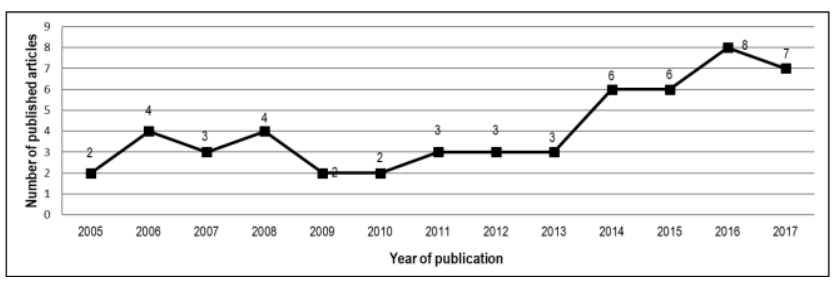

Figure 2. Classification of Articles by Year of Publication

The distribution of the most frequently used keywords is depicted in Figure 3. As the keywords show, the support of decision processes in manufacturing is based on support systems and optimization methods to describe uncertainties and behavior.

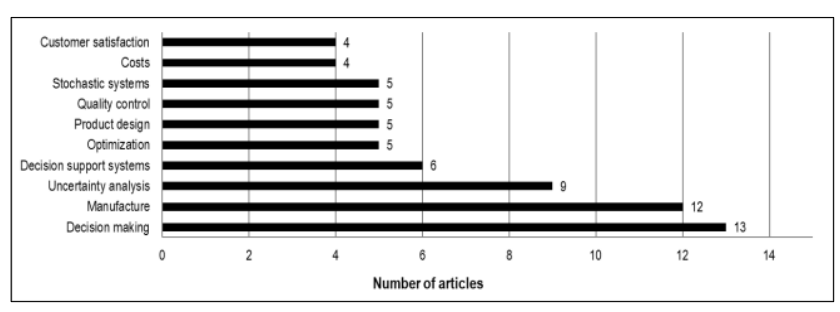

Figure 3. Classification of Articles Considering the Used Keywords

We analyzed the articles from the point of view of scientific impact. The most usual form to evaluate articles from the point of view of scientific impact is the citation. Figure 4. shows the 10 most cited articles with their number of citations.

Quality related decisions are represented in all fields of supply chain: purchasing and procurement (Jin et al., 2014; Tang \& Hsu, 2015), manufacturing and assembly (Chang et al., 2008; Shukla et al., 2015), distribution (Zhang et al., 2016) and inverse processes like reverse supply chain (Pochampally \& Gupta, 2005), life cycle assessment and end-of-life analysis of used products (Yao et al., 2010; Deng et al., 2017) and product development (Summers \&
Scherpereel, 2008), recovery (Dehghanbaghi et al., 2016) and defect removal problems (Kucharska et al., 2017).

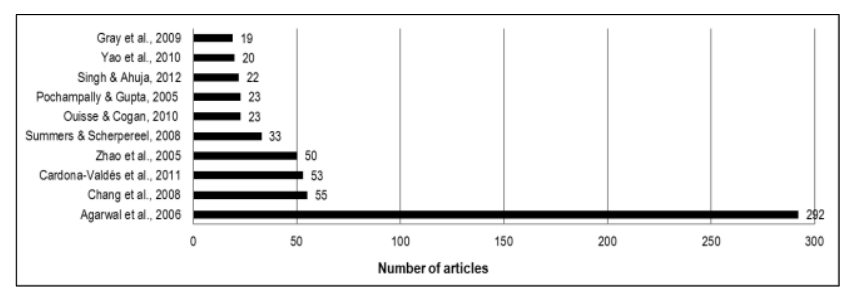

Figure 4. The 10 Most Cited Articles Based on the Search in Scopus Database

Global competition and increased product variety has collectively forced the manufacturing enterprises and their logistics providers to strength the cooperation and networking through hyperconnected global logistics system (Banyai et al., 2018). Manufacturing and logistics systems are hyperconnected, when their agents are connected on multiple layers. Cooperation and networking can be seen from a wide range of aspects, like multi-agent coordination in networked manufacturing processes (Chan et al., 2007), design and operation of manufacturing networks (Mourtzis et al., 2015), worldwide production network analysis (Kuhn, 2006), strategies for sharing of manufacturing resources (Kondoh \& Salmi, 2011). However, the networking approach can be described as an agile supply chain solution (Agarwal et al., 2006), and uncertainty makes the design of supply chain processes more and more complex (CardonaValdes et al., 2011), but the integration of procurement, manufacturing, distributions and reverse processes is unavoidable (Xu et al., 2013).

Decision making with uncertain quality is a living optimization problem both in the field of production like automotive industry (Ouisse \& Cogan, 2010), food processing (Curt et al., 2007), petrochemical industry (Moradi-Aliabadi \& Huang, 2016), TV panel manufacturing (Tang \& Hsu, 2015) and creating of high-tech/high-value products (Batkovskiy et al., 2016) and services (Jiang \& Seidmann, 2014; Drejeriene \& Drejeris, 2017). The economics of decisions includes other special application fields, like evaluation of the factors determining risk of growing current account deficit (Garšviene \& Cibulskiene, 2017) or the modelling of financial market volatility (Chin et al., 2016).

The measurement and evaluation of quality and quality influenced processes is an area of research which has seen remarkable growth over the last few years. Researchers investigated new evaluation and measurement methods and tools to identify the impact of quality on products, processes and costs (Loftus \& Giudice, 2014). Reliability is also strongly influenced by quality (Amuthakkannan et al., 2009) and inspection processes have a measurable impact on quality as well (Mohammadi et al., 2015). The evaluation is especially important in complex automatized production facilities like flexible manufacturing plants (Ervural et al., 2016; Aghdaie et al., 2013).

There are many reasons to outsource manufacturing and logistics operations, like lower operational and labor costs, freeing up internal resources or core competences for more value-added processes, delegate responsibilities and add manufacturing resources to increase the fulfilment rate of 
orders (Banyai, 2017). Empirical analyses show the impact of outsourcing on cost and quality (Gray et al., 2009). In this context, the principles of business management underline the importance of determining beneficial outsourcing options at the strategic level and optimize the planning at the tactical level of manufacturing and logistics (Hahn et al., 2016). Quality house model is constructed to describe the dependent and feedback relationships among the factors, such as customer's demands, product quality, process quality, quality assurance issues (Kuntiyawichai \& Limkatanyu, 2006) and economic aspects. In the case of stochastic quality performance, fuzzy data envelopment analysis can be used to describe uncertainties of the processes (Sarina et al., 2012). Quality chain design and control is generally based on multi-stage decision making (Zhao et al., 2005; Hejazi et al., 2017). Not only technological (Molnar, 2017; Kundrak et al., 2013) but also logistics related parameters can have a great impact on quality: the leaders' spiritual intelligence influences the service quality of organization research (Silingiene \& Skeriene, 2016), and hidden costs have to be taken into consideration while evaluating quality failure costs (Snieska et al., 2013).

It remains a key challenge for companies to make the best decisions related to uncertain quality required to fulfil economic and logistic requirements. In recent years there have been many studies solving decision making problems related to uncertain behaviors in manufacturing processes using analytical methods (Kaur et al., 2015; Wudhikarn et al., 2015), statistical techniques (Villeta et al., 2012), fuzzy approaches (Tseng \& Lin, 2008; Noori et al., 2008; Cheng et al., 2007; Sayyadi Tooranloo \& Ayatollah, 2016). Empirical evidence is also used in the research $(\mathrm{Su} \&$ Linderman, 2016), and neural network applications also show robust directions of stochastic quality based manufacturing problems (Feng et al., 2006). Single and multiobjective optimization algorithms are also used not only in the field of engineering problems (Jarmai, 2007), but also in the field of decision making.

More than $50 \%$ of the articles were published in the last 5 years. This result indicates the scientific potential of this research field. The articles that addressed the optimization of in-plant decisions are focusing on economic lot sampling (Fernandez, 2017), analysis of group behavior in uncertain quality function deployment (Yan et al., 2014) and pricing (Yu \& Ma, 2013), but none of the articles aimed to identify the optimization aspects of in-plant decisions depending on the quality of components. Therefore, impact of uncertain qualities on manufacturing operations and processes still needs more attention and research.

It was found that decision making tools and models (Singh \& Ahuja, 2012; Samantra et al., 2013; Orji \& Wei, 2014) are important for optimization of manufacturing processes since a wide range of quality related decisions determine a complex stochastic optimization problem. According to that, the main focus of this research is the modelling and analysis of economic aspects of decision making in production processes with uncertain component quality, also taking into account the multi-component decisions.
The main contribution of this article to the literature includes: (1) the model framework of decisions in production processes with uncertain quality; (2) definition of a new enhanced decision tree model with stochastic parameters described by cumulative hypergeometric probability distributions that can determine the optimal operations depending on the quality of components to be assembled; (3) mathematical descriptions of decisions related to the optimal pre-assembly operation, like testing or repairing; (4) computational results of the described model with different datasets.

\section{Modelling of Decisions Caused by Uncertain Quality of Components}

Within the frame of this session the decision making model of a manufacturing process with uncertain component quality is described. The manufacturing plant produces printed circuit boards (PCBs) with wave soldering technology in a batch size of $\mathrm{N}$, where circuit boards are passed over a pan of waving molten solder and the components become soldered to the board contacting with the waving solder. Wave soldering production lines can produce defecting PCBs with a high probability, because a wide range of problems can be occurred, like bridging, insufficient solder, non-wetting, blow and pin holes, solder skips, flags or lifted components. From experience, $p_{Q_{1}}$ percentage of all batches contains $M_{Q_{1}}$ defective PCBs and is qualified as $1^{\text {st }}$ class batch, while $p_{Q_{2}}$ percentage of all batches contains $M_{Q_{2}}$ defective PCBs and is qualified as $2^{\text {nd }}$ class batches. PCBs are transported to an assembly plant, where automated test platforms are assembled. The assembly cost depends on the quality of PCBs, because assembled defective PCBs must be after post-assembly test of the automated test platform removed, tested and repaired manually. The assembly cost of $1^{\text {st }}$ class quality batch PCBs is $c_{Q_{1}}^{A}$ and the same cost of $2^{\text {nd }}$ class quality $\mathrm{PCBs}$ is $c_{Q_{2}}^{A}$. There is a possibility to test the quality of produced batches with a without replacement method, where the costs of testing is $c^{T}$ for each item to determine the quality of the batch. It is possible to repair $2^{\text {nd }}$ class quality batches for a costs of $c^{R}$. However binomial probability distribution is a good approximation of hypergeometric probability distribution as long as the size of the sample is less than about $10 \%$ of the population, but because of the dynamical size of the sample we are using hypergeometric distribution (Figure 5).

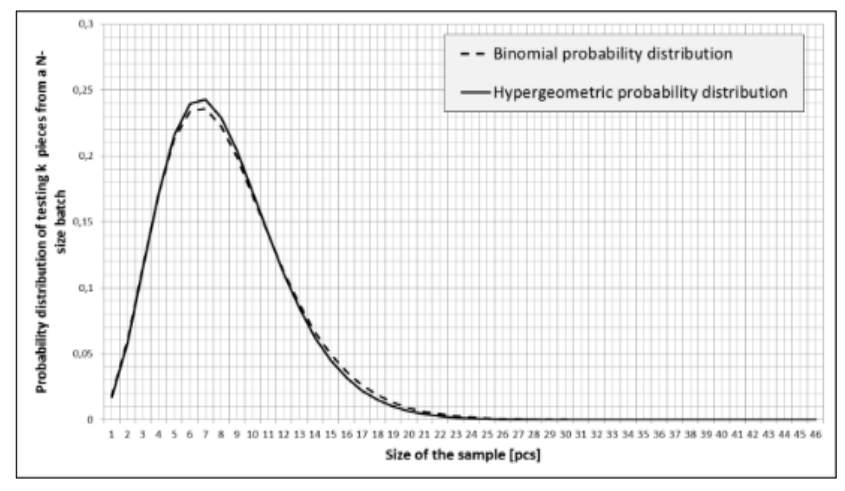

Figure 5. Binomial and Hypergeometric Probability Distribution of Identify $k$ Defective Component from $n$ tests 
As Figure 6 shows, the difference between the two different distributions are increasing almost exponentially as the size of the sample is increasing.

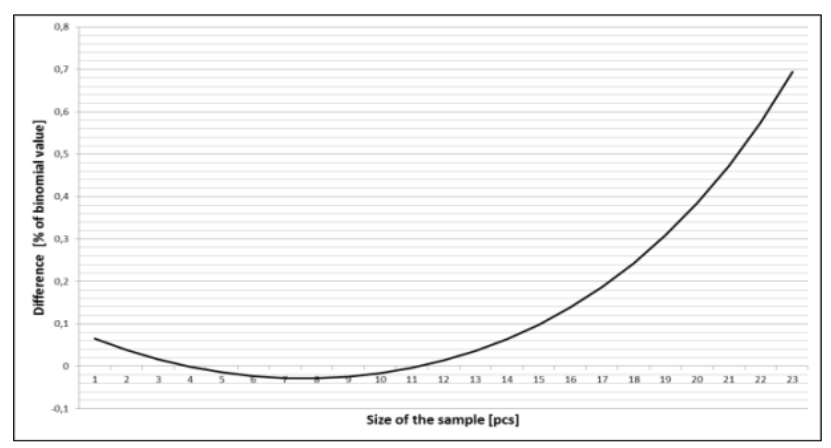

Figure 6. Differences between the Binomial and Hypergeometric Probability Distribution

As Figure 7 demonstrates, the difference between the two different distributions depends on the proportion of defective components. If the proportion of defective components is lower, than the binomial probability distribution approximates the hypergeometric probability distribution in the case of bigger sample sizes better. Therefore, hypergeometric distribution function can be seen as a good distribution function to model the above described decision problem.

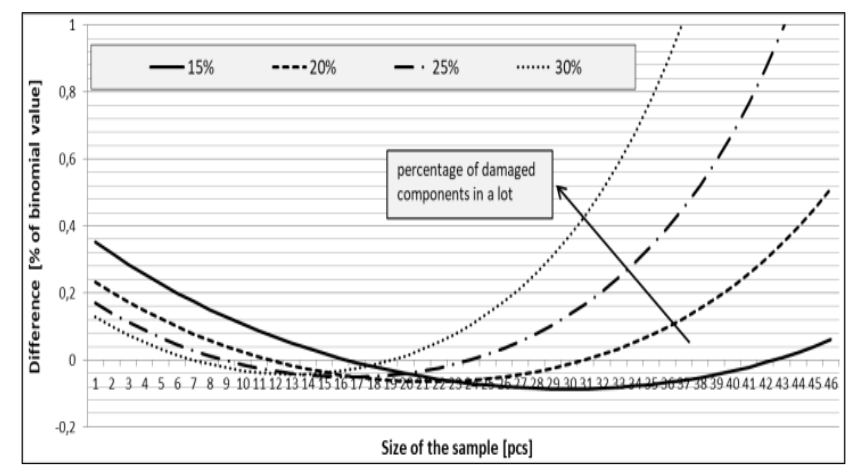

Figure 7. Differences between the Binomial and Hypergeometric Probability Distribution Depending on the Number of Defected Components

The probability, that an $n$-trial test process without replacement results $k$ defective components from the $1^{\text {st }}$ class quality batch, when the batch consist of $N$ items, $M_{G}$ of which are classified as defected components may be written as

$$
p\left(n_{D}=k \mid Q_{1}\right)=\frac{\left(\begin{array}{c}
M_{Q_{1}} \\
k
\end{array}\right)\left(\begin{array}{c}
N-M_{Q_{1}} \\
n-k
\end{array}\right)}{\left(\begin{array}{c}
N \\
n
\end{array}\right)} .
$$

The probability, that an $n$-trial test process without replacement results $k$ non-defective components from the $1^{\text {st }}$ class quality batch, when the batch consist of $N$ items, $M_{Q_{1}}$ of which are classified as defected components may be written as

$$
p\left(n_{N D}=k \mid Q_{1}\right)=\frac{\left(\begin{array}{c}
M_{Q_{1}} \\
n-k
\end{array}\right)\left(\begin{array}{c}
N-M_{Q_{1}} \\
k
\end{array}\right)}{\left(\begin{array}{l}
N \\
n
\end{array}\right)} .
$$

The probability, that an $n$-trial test process without replacement results $k$ defective components from the $2^{\text {nd }}$ class quality batch, when the batch consist of $N$ items, $M_{Q_{2}}$ of which are classified as defected components may be written as

$$
p\left(n_{D}=k \mid Q_{2}\right)=\frac{\left(\begin{array}{c}
M_{Q_{2}} \\
k
\end{array}\right)\left(\begin{array}{c}
N-M_{Q_{2}} \\
n-k
\end{array}\right)}{\left(\begin{array}{c}
N \\
n
\end{array}\right)} .
$$

The probability, that an $n$-trial test process without replacement results $k$ non-defective components from the $2^{\text {nd }}$ class quality batch, when the batch consist of $N$ items, $M_{Q_{2}}$ of which are classified as defected components may be written as

$$
p\left(n_{N D}=k \mid Q_{2}\right)=\frac{\left(\begin{array}{c}
M_{Q_{2}} \\
n-k
\end{array}\right)\left(\begin{array}{c}
N-M_{Q_{2}} \\
k
\end{array}\right)}{\left(\begin{array}{l}
N \\
n
\end{array}\right)} .
$$

The probability, that the $k$ defective components are resulted from the $1^{\text {st }}$ class quality batch may be written as

$$
p\left(n_{D}=k \cap Q_{1}\right)=p\left(Q_{1}\right) \frac{\left(\begin{array}{c}
M_{Q_{1}} \\
k
\end{array}\right)\left(\begin{array}{c}
N-M_{Q_{1}} \\
n-k
\end{array}\right)}{\left(\begin{array}{l}
N \\
n
\end{array}\right)} .
$$

The probability, that the $k$ defective components are resulted from the $2^{\text {nd }}$ class quality batch may be written as

$$
p\left(n_{D}=k \cap Q_{2}\right)=p\left(Q_{2}\right) \frac{\left(\begin{array}{c}
M_{Q_{2}} \\
k
\end{array}\right)\left(\begin{array}{c}
N-M_{Q_{2}} \\
n-k
\end{array}\right)}{\left(\begin{array}{c}
N \\
n
\end{array}\right)} .
$$

The probability, that the $k$ non-defective components are resulted from the $1^{\text {st }}$ class quality batch may be written as

$$
p\left(n_{N D}=k \cap Q_{1}\right)=p\left(Q_{1}\right) \frac{\left(\begin{array}{l}
M_{Q_{1}} \\
n-k
\end{array}\right)\left(\begin{array}{l}
N-M_{Q_{1}} \\
k
\end{array}\right)}{\left(\begin{array}{l}
N \\
n
\end{array}\right)} .
$$

The probability, that the $k$ non-defective components are resulted from the $2^{\text {nd }}$ class quality batch may be written as

$$
p\left(n_{N D}=k \cap Q_{2}\right)=p\left(Q_{2}\right) \frac{\left(\begin{array}{l}
M_{Q_{2}} \\
n-k
\end{array}\right)\left(\begin{array}{c}
N-M_{Q_{2}} \\
k
\end{array}\right)}{\left(\begin{array}{l}
N \\
n
\end{array}\right)} .
$$

The probability, that the $k$ defective components are resulted from the $n$-trial test process without replacement may be written as

$$
\begin{aligned}
& p\left(n_{D}=k\right)=p\left(n_{D}=k \cap Q_{1}\right)+p\left(n_{D}=k \cap Q_{2}\right)= \\
& \frac{p\left(Q_{1}\right)\left(\begin{array}{c}
M_{Q_{1}} \\
k
\end{array}\right)\left(\begin{array}{c}
N-M_{Q_{1}} \\
n-k
\end{array}\right)+p\left(Q_{2}\right)\left(\begin{array}{c}
M_{Q_{2}} \\
k
\end{array}\right)\left(\begin{array}{c}
N-M_{Q_{2}} \\
n-k
\end{array}\right)}{\left(\begin{array}{c}
N \\
n
\end{array}\right)}
\end{aligned}
$$

The probability, that the $k$ non-defective components are resulted from the $n$-trial test process without replacement may be written as

$$
\begin{aligned}
& p\left(n_{N D}=k\right)=p\left(n_{N D}=k \cap Q_{1}\right)+p\left(n_{N D}=k \cap Q_{2}\right)= \\
& p \frac{p\left(Q_{1}\right)\left(\begin{array}{c}
M_{Q_{1}} \\
n-k
\end{array}\right)\left(\begin{array}{c}
N-M_{Q_{1}} \\
k
\end{array}\right)+p\left(Q_{2}\right)\left(\begin{array}{c}
M_{Q_{2}} \\
n-k
\end{array}\right)\left(\begin{array}{c}
N-M_{Q_{2}} \\
k
\end{array}\right)}{\left(\begin{array}{l}
N \\
n
\end{array}\right)}
\end{aligned}
$$

So long as $k$ defective components are resulted from the $n$-trial test process, the posterior probability of testing a $2^{\text {nd }}$ class quality batch may be written as

$$
\begin{gathered}
p\left(Q_{2} \mid n_{D}=k\right)=\frac{p\left(n_{D}=k \cap Q_{2}\right)}{p\left(n_{D}=k\right)}= \\
\frac{p\left(Q_{2}\right)\left(\begin{array}{c}
M_{Q_{2}} \\
k
\end{array}\right)\left(\begin{array}{c}
N-M_{Q_{2}} \\
n-k
\end{array}\right)}{p\left(Q_{1}\right)\left(\begin{array}{c}
M_{Q_{1}} \\
k
\end{array}\right)\left(\begin{array}{c}
N-M_{Q_{1}} \\
n-k
\end{array}\right)+p\left(Q_{2}\right)\left(\begin{array}{c}
M_{Q_{2}} \\
k
\end{array}\right)\left(\begin{array}{c}
N-M_{Q_{2}} \\
n-k
\end{array}\right)}
\end{gathered}
$$

So long as $k$ defective components are resulted from the $n$-trial test process, the posterior probability of testing a $1^{\text {st }}$ class quality batch may be written as

$$
\begin{gathered}
p\left(Q_{1} \mid n_{D}=k\right)=\frac{p\left(n_{D}=k \cap Q_{1}\right)}{p\left(n_{D}=k\right)}= \\
\frac{p\left(Q_{1}\right)\left(\begin{array}{c}
M_{Q_{1}} \\
k
\end{array}\right)\left(\begin{array}{c}
N-M_{Q_{1}} \\
n-k
\end{array}\right)}{p\left(Q_{1}\right)\left(\begin{array}{c}
M_{Q_{1}} \\
k
\end{array}\right)\left(\begin{array}{c}
N-M_{Q_{1}} \\
n-k
\end{array}\right)+p\left(Q_{2}\right)\left(\begin{array}{c}
M_{Q_{2}} \\
k
\end{array}\right)\left(\begin{array}{c}
N-M_{Q_{2}} \\
n-k
\end{array}\right)}
\end{gathered}
$$


So long as $k$ non-defective components are resulted from the $n$-trial test process, the posterior probability of testing a $2^{\text {nd }}$ class quality batch may be written as

$$
\begin{aligned}
& p\left(Q_{2} \mid n_{N D}=k\right)=\frac{p\left(n_{N D}=k \cap B\right)}{p\left(n_{N D}=k\right)}= \\
& \frac{p\left(Q_{2}\right)\left(\begin{array}{c}
M_{Q_{2}} \\
n-k
\end{array}\right)\left(\begin{array}{c}
N-M_{Q_{2}} \\
k
\end{array}\right)}{p\left(Q_{1}\right)\left(\begin{array}{c}
M_{Q_{1}} \\
n-k
\end{array}\right)\left(\begin{array}{c}
N-M_{Q_{1}} \\
k
\end{array}\right)+p(B)\left(\begin{array}{c}
M_{Q_{2}} \\
n-k
\end{array}\right)\left(\begin{array}{c}
N-M_{Q_{2}} \\
k
\end{array}\right)}
\end{aligned}
$$

So long as $k$ non-defective components are resulted from the $n$-trial test process, the posterior probability of testing a $1^{\text {st }}$ class quality batch may be written as

$$
\begin{aligned}
& p\left(Q_{1} \mid n_{N D}=k\right)=\frac{p\left(n_{N D}=k \cap Q_{1}\right)}{p\left(n_{N D}=k\right)}= \\
& \frac{p\left(Q_{1}\right)\left(\begin{array}{l}
M_{Q_{1}} \\
n-k
\end{array}\right)\left(\begin{array}{c}
N-M_{Q_{1}} \\
k
\end{array}\right)}{p\left(Q_{1}\right)\left(\begin{array}{c}
M_{Q_{1}} \\
n-k
\end{array}\right)\left(\begin{array}{c}
N-M_{Q_{1}} \\
k
\end{array}\right)+p\left(Q_{2}\right)\left(\begin{array}{l}
M_{Q_{2}} \\
n-k
\end{array}\right)\left(\begin{array}{c}
N-M_{Q_{2}} \\
k
\end{array}\right)}
\end{aligned}
$$

The expected cost of assembling batches without testing or repairing (direct assembly) can be calculated as

$$
c^{D A}=p_{Q_{1}} c_{Q_{1}}^{A}+p_{Q_{2}} c_{Q_{2}}^{A} \text {. }
$$

The expected cost of assembling batches after repairing without test can be calculated as

$$
c^{I D A}=c_{Q_{1}}^{A}+c^{R} \text {. }
$$

The expected cost of assembling batches after testing and repairing if necessary can be calculated as

$$
{ }_{c}^{A T R}=\sum_{k=0}^{n} p\left(n_{D}=k\right) \text {. }
$$

$$
\min \left(\begin{array}{c}
p\left(Q_{1} \mid n_{D}=k\right)\left(c_{Q_{1}}^{A}+n c^{T}\right)+ \\
p\left(Q_{2} \mid n_{D}=k\right)\left(c_{Q_{2}}^{A}+n c^{T}\right) ; c_{Q_{1}}^{A}+c^{T}+c^{R}
\end{array}\right)
$$

We then compute the expected cost after the best decision as

$$
\begin{aligned}
& c^{\text {opt }}=\min \left(c^{D A} ; c^{I D A} ; c^{A T R}\right), \\
& \text { which can be written as } \\
& c^{\text {opt }}=\min \left(p_{Q_{1}} c_{Q_{1}}^{A}+p_{Q_{2}} c_{Q_{2}}^{A} ; c_{Q_{1}}^{A}+c^{R} ; \sum_{k=0}^{n} p\left(n_{D}=\right.\right. \\
& \left.k) \cdot \min \left(\begin{array}{c}
p\left(Q_{1} \mid n_{D}=k\right)\left(c_{Q_{1}}^{A}+n c^{T}\right)+ \\
p\left(Q_{2} \mid n_{D}=k\right)\left(c_{Q_{2}}^{A}+n c^{T}\right) ; c_{Q_{1}}^{A}+c^{T}+c^{R}
\end{array}\right)\right) .
\end{aligned}
$$

Considering the above described mathematical model, the modified decision tree using hypergeometric distribution functions makes it possible to find the optimal processing varieties and testing/sampling strategy to optimize the total processing costs of components required for assembly.

\section{Numerical Analysis and Results}

The above described model makes it possible to make optimal decisions to minimize the cost of the assembly of the final products from components with uncertain quality. Within the frame of this section, two scenarios will be analyzed. Figure 8 demonstrates the general structure of the decision tree with hypergeometric distribution function of quality related parameters.

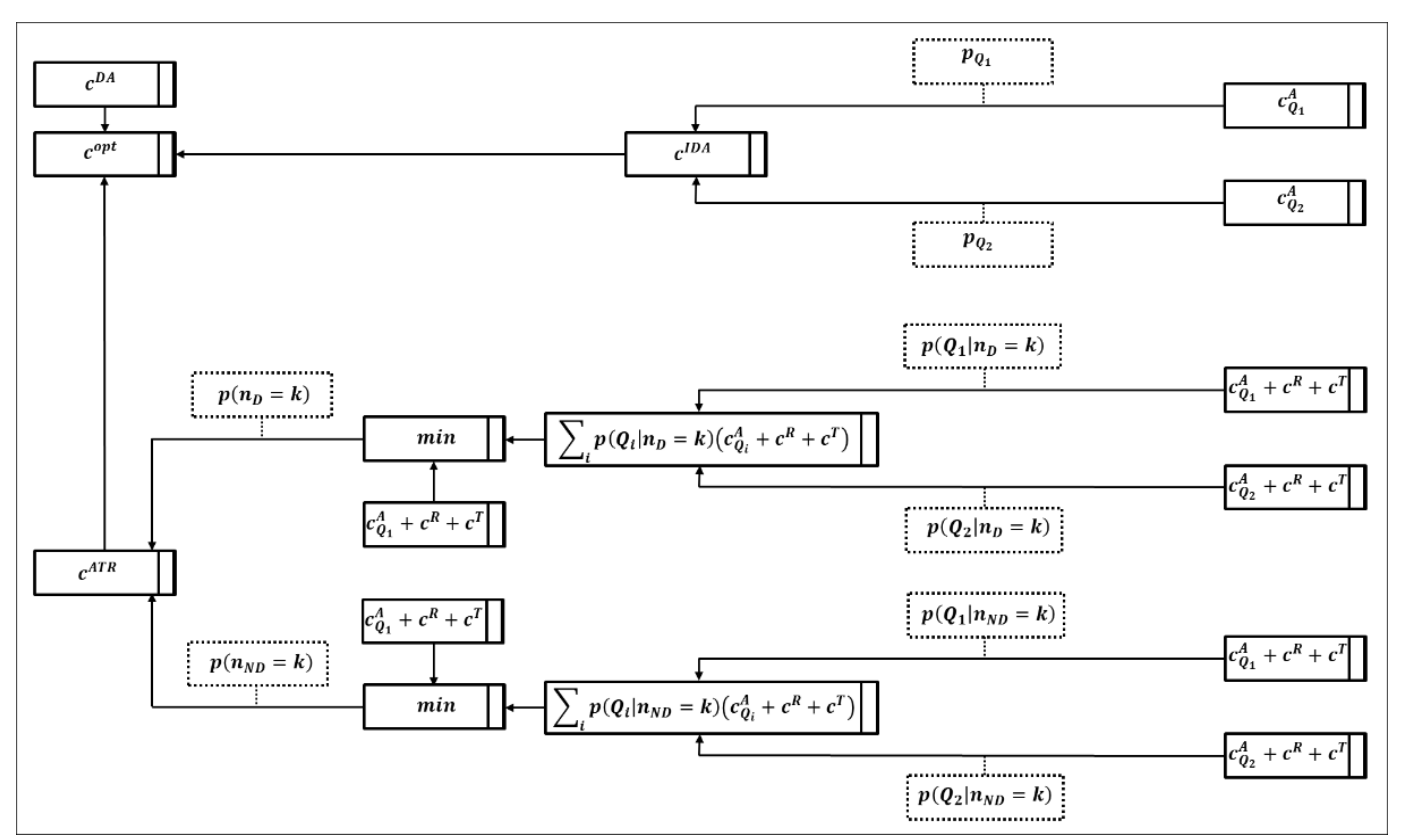

Figure 8. Decision tree Including Posterior Probabilities

The $1^{\text {st }}$ scenario describes a general two components model with dataset described in Table 1 . In the case of the $1^{\text {st }}$ scenario the manufacturer produces two different components and these two components will be assembled into a final product. In the case of the $1^{\text {st }}$ component, $75 \%$ of the batches contains $10 \%$ defective components and are qualified as $1^{\text {st }}$ class batch, while $25 \%$ of the batches contains $50 \%$ defective components with hypergeometric distribution and are qualified as $2^{\text {nd }}$ class batches.

Dataset of the $1^{\text {st }}$ Scenario

\begin{tabular}{lllllllll}
\hline & $\mathbf{p}_{Q_{1}}$ & $\mathbf{p}_{Q_{2}}$ & $\mathbf{M}_{Q_{1}}$ & $\mathbf{M}_{Q_{2}}$ & $\mathbf{c}_{Q_{1}}^{A}$ & $\mathbf{c}_{Q_{2}}^{A}$ & $\boldsymbol{c}^{\boldsymbol{R}}$ & $\boldsymbol{c}^{\boldsymbol{T}}$ \\
\hline Component 1 & 0.75 & 0.25 & 0.10 & 0.50 & 100 & 800 & 200 & 20 \\
\hline Component 2 & 0.20 & 0.80 & 0.25 & 0.60 & 80 & 250 & 80 & 40 \\
\hline
\end{tabular}


The assembly cost of $1^{\text {st }}$ class quality batch PCBs is 100 $\$$ and the same cost of $2^{\text {nd }}$ class quality components is 800 $\$$. The costs of testing is $20 \$$ for each item to determine the quality of the batch and the repairing cost is $200 \$$ for $2^{\text {nd }}$ class quality batches. In the case of the $2^{\text {nd }}$ component, 20 $\%$ of the batches contains $10 \%$ defective components and are qualified as $1^{\text {st }}$ class batch, while $25 \%$ of the batches contains $50 \%$ defective components with hypergeometric distribution and are qualified as $2^{\text {nd }}$ class batches. The assembly cost of 1 st class quality batch PCBs is $100 \$$ and the same cost of $2^{\text {nd }}$ class quality components is $800 \$$. The costs of testing is $20 \$$ for each item to determine the quality of the batch and the repairing cost is $200 \$$ for $2^{\text {nd }}$ class quality batches.

As Figure 9 shows, the best decision in this scenario is the testing of all batches with a cost of $247,5 \$$, while the cost of assembling without test and reworking is $275 \$$ and the cost of reworking without test is 275 \$.

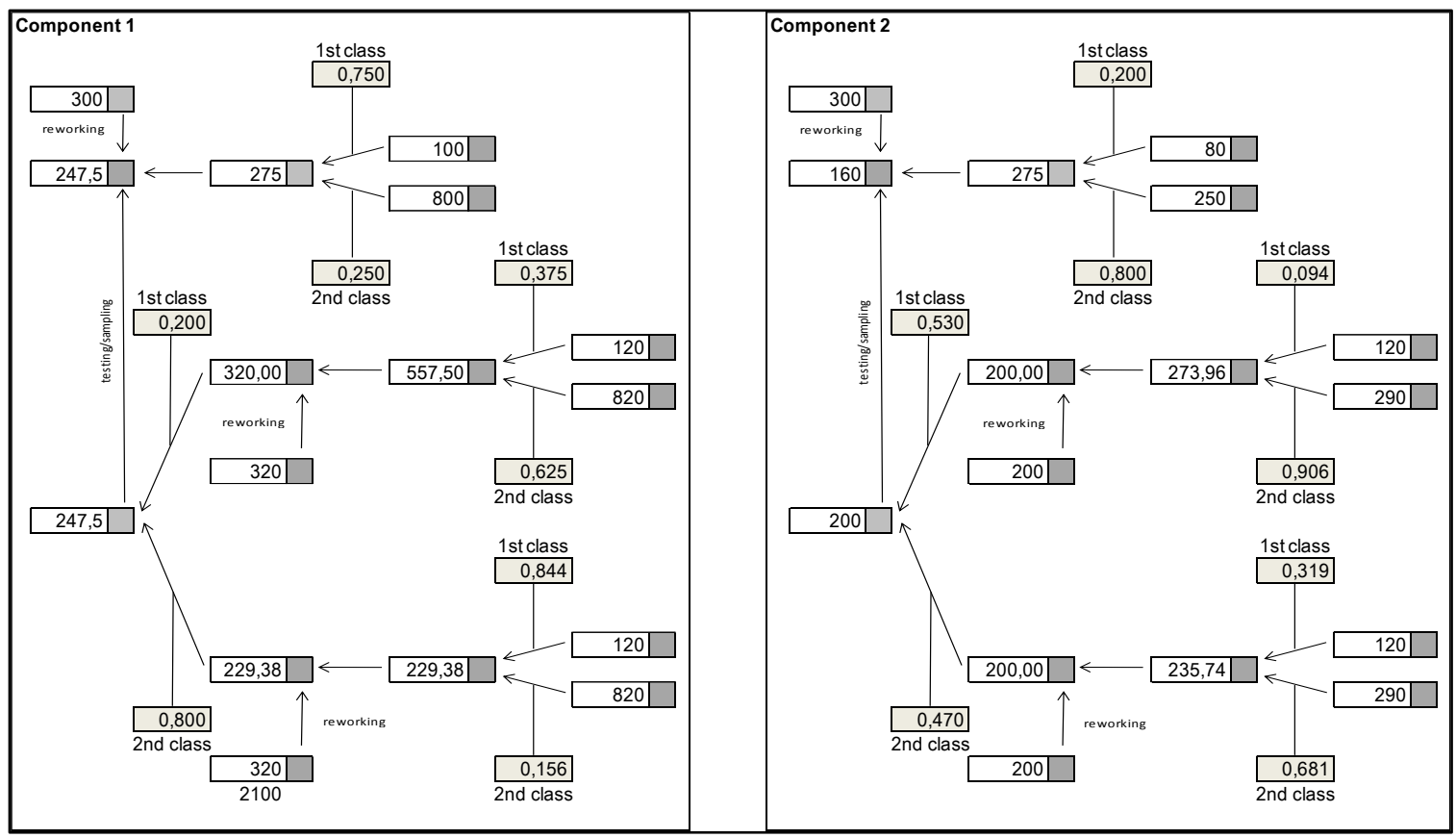

Figure 9. Differences between the Binomial and Hypergeometric Probability Distribution Depending on the Number of Defected Components

The decision making process can be evaluated from the point of view of value of information (Winston, 1994). The expected value with sample information (EVWSI) describes the final asset position. EVWSI are defined as:

$E V W S I=c^{A T R}-\mathrm{c}^{T}$.

If the test market study is not available, we can calculate the expected value with original information (EVWOI) as defined:

EVWOI $=c^{D A}=p_{Q_{1}} c_{Q_{1}}^{A}+p_{Q_{2}} c_{Q_{2}}^{A}$.

The expected value of the sample information is the difference of the expected value with sample information and original information:

EVSI $=E V W S I=c^{A T R}-c^{T}-p_{Q_{1}} c_{Q_{1}}^{A}-p_{Q_{2}} c_{Q_{2}}^{A}$.

The expected value of perfect information can be calculated as follows:

$$
\begin{aligned}
& E V P I=\mathrm{p}_{Q_{1}} \min \left(\mathrm{c}_{Q_{1}}^{A}, \mathrm{c}_{Q_{1}}^{A}+c^{R}\right)+ \\
& \mathrm{p}_{Q_{2}} \min \left(\mathrm{c}_{Q_{2}}^{A}, \mathrm{c}_{Q_{1}}^{A}+c^{R}\right)= \\
& \mathrm{p}_{Q_{1}}\left(\min \left(\mathrm{c}_{Q_{1}}^{A}, \mathrm{c}_{Q_{1}}^{A}+c^{R}\right)-\mathrm{c}_{Q_{1}}^{A}\right)+ \\
& \mathrm{p}_{Q_{2}}\left(\min \left(\mathrm{c}_{Q_{2}}^{A}, \mathrm{c}_{Q_{1}}^{A}+c^{R}\right)-\mathrm{c}_{Q_{2}}^{A}\right)
\end{aligned}
$$

where $\mathrm{p}_{Q_{1}}$ and $\mathrm{p}_{Q_{2}}$ are hypergeometric distribution functions.

In this $1^{\text {st }}$ scenario EVWSI=227.5 \$, EVWOI=275 \$, EVSI=47.5 \$, EVWPI=150 $\$$ and EVPI=125 $\$$ for the $1 \mathrm{st}$ component and EVWSI=160 \$, EVWOI=216 \$, EVSI=56 $\$, E V W P I=144 \$$ and EVPI=72 $\$$ for the 2 nd component.
In the $2^{\text {nd }}$ scenario we are analyzing the impact of parameters, especially the prior probability of $1^{\text {st }}$ class and $2^{\text {nd }}$ class batches. As Figure 10 demonstrates, the function of quality of components to assembled to final products and posterior probabilities used in the decision tree based on hypergeometric distribution functions are no longer linear.

As Figure 11 shows, the processing cost depends on the prior probabilities of the $1^{\text {st }}$ class batches and there are two significant values of them, where the optimal processing strategy is changed.

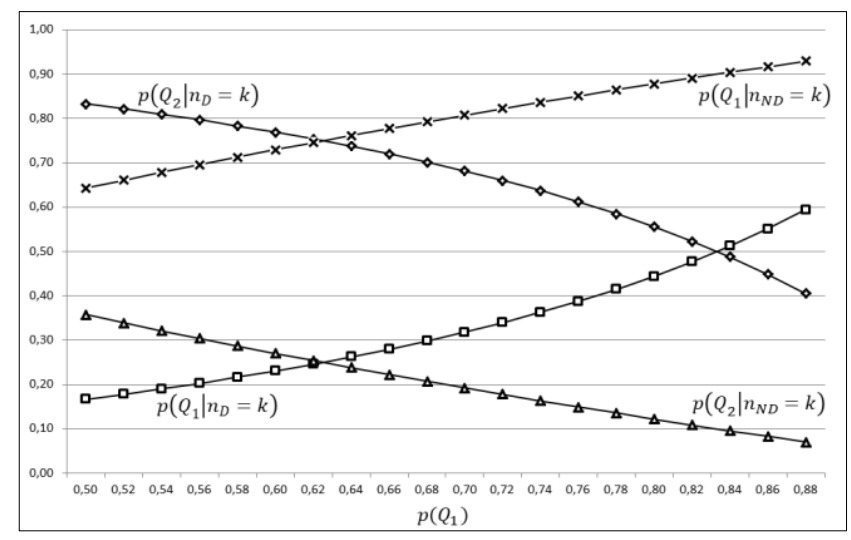

Figure 10. Impact of Prior Probability of $1^{\text {st }}$ Quality Batches on the Posterior Probabilities 


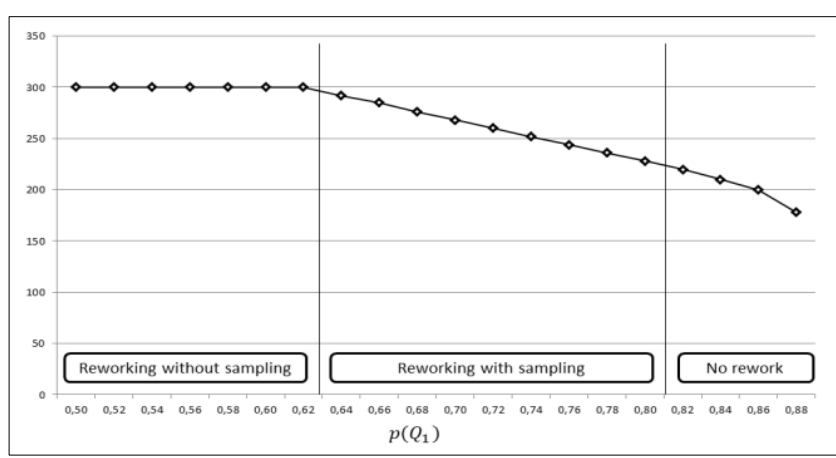

Figure 11. Processing cost Depending on the Prior Probability of $1^{\text {st }}$ Quality Batches

In this scenario the first point, where processing strategy is changed is the $\mathrm{p}_{Q_{1}}=0.62$. Under this value the optimal strategy is the reworking of all components. The second value is $\mathrm{p}_{Q_{1}}=0.82$, above this value no rework is necessary, because of the high ratio of $1^{\text {st }}$ class batches. Between these two values sampling is necessary to make the optimal decision.

As Figure 12 shows, the value of information is increasing depending on the prior probability of $1^{\text {st }}$ class quality batches. The ranking order of the values of information at the value of $\mathrm{p}_{Q_{1}}=0.50$ are $E V S I<$ EVWPI $<E V P I<E V W S I<E V W O I$. This ranking order is changed at a specific point of the prior probability $\mathrm{p}_{Q_{1}}=$ 0.67 and the new ranking order of values of information are EVSI $<E V P I<E V W P I<E V W S I<E V W O I$.

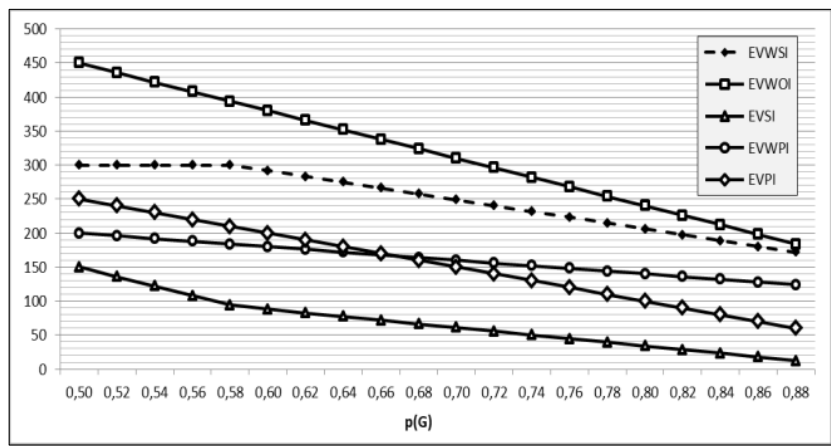

Figure 12. Value of Information from Different Aspects Depending on the Prior Probability of $1^{\text {st }}$ Quality Batches

\section{Conclusions}

This study developed a methodological approach for optimization of processing strategies in manufacturing systems with uncertain component quality. In this paper, firstly we review and systematically categorized the recent works presented for processing components with uncertain quality. Then, motivated from the gaps in the literature, a model to support decision making is developed. The model describes a new approach using hypergeometric distribution functions instead of normal or binomial distributions to describe the uncertainties of quality. The developed decision tree can be multiplied and used for the optimization and evaluation of quality related manufacturing processes for assembly. The scenario analysis showed the efficiency of the described model and algorithm. The scientific contributions of this paper are the followings: integrated model for decision making in manufacturing processes to find the optimal processing for components with uncertain qualities; description of the impact of quality on the value of information caused by sampling/testing; description of the uncertain quality with hypergeometric distribution function. Hypergeometric distribution function makes it possible to vary the parameters of sampling and the required lots of sampling can be also optimized from the point of view quality control costs. The results can be generalized, because the model can be applied for a wide range of manufacturing technologies. The described methods make it possible to support managerial decisions; the operation strategy of the manufacturing can be influenced by the results of the above described contribution. However, there are also directions for further research. First, although the assembly of components is considered in this paper, the capacities of assembling and sampling are not taken into consideration. In further studies, the model can be extended to a more complex model including capacities and time windows (Banyai et al., 2018). Enterprise resource planning (ERP) systems are developed to manage and integrate business processes across organizational functions and locations. Finally this approach might be useful for further studies aiming the deeper integration of quality into ERP systems, where the growing importance of ERP integration is essential for increased efficiency and availability of manufacturing systems.

\section{References}

Agarwal, A., Shankar, R., \& Tiwari, M. K. (2006). Modeling the metrics of lean, agile and leagile supply chain: An ANPbased approach. European Journal of Operational Research, 173(1), 211-225. https://doi.org/10.1016/ j.ejor.2004.12.005

Aghdaie, M. H., Zolfani, S. H., \& Zavadskas, E. K. (2013). Decision making in machine tool selection: an integrated approach with SWARA and COPRAS-G methods. Inzinerine Ekonomika-Engineering Economics, 24(1), 5-17. https://doi.org/10.5755/j01.ee.24.1.2822

Amuthakkannan, R., Kannan, S. M., Vijayalakshmi, K., \& Ramaraj, N. (2009). Reliability analysis of programmable mechatronics system using Bayesian approach. International Journal of Industrial and Systems Engineering, 4(3), 303-325. https://doi.org/10.1504/IJISE.2009.023544

Banyai, T. (2017). Supply Chain Optimization of Outsourced Blending Technologies. Journal of Applied Economic Sciences, 12(4), 960-976.

Banyai, T., Telek, P., \& Landschutzer, C. (2018, May). Milkrun Based In-plant Supply-An Automotive Approach. In Vehicle and Automotive Engineering (pp. 170-185). Springer, Cham. https://doi.org/10.1007/978-3-319-75677-6_14 
Banyaine Toth, A., Illes, B., \& Schenk, F. (2017). Supply Chain Design of Manufacturing Processes with Blending Technologies. Solid State Phenomena, 261, 509-515. https://doi.org/10.4028/www.scientific.net/SSP.261.509

Batkovskiy, A. M., Semenova, E. G., Fomina, A. V., Khrustalev, E. I., \& Khrustalev, O. E. (2016). The methodology and mathematical tools to assess and mitigate the risk of creating high-tech products. Indian Journal of Science and Technology, 9(28), 97659. https://doi.org/10.17485/ijst/2016/v9i28/97659

Cardona-Valdes, Y., Alvarez, A., \& Ozdemir, D. (2011). A bi-objective supply chain design problem with uncertainty. Transportation Research Part C: Emerging Technologies, 19(5), 821-832. https://doi.org/ 10.1016/j.trc.2010.04.003

Chan, F. T. S., Swarnkar, R., \& Tiwari, M. K. (2007). Infrastructure for co-ordination of multi-agents in a network-based manufacturing system. International Journal of Advanced Manufacturing Technology, 31(9/10), 1028-1033. https://doi.org/10.1007/s00170-005-0115-9

Chang, C. W., Wu, C. R., \& Chen, H. C. (2008). Using expert technology to select unstable slicing machine to control wafer slicing quality via fuzzy AHP. Expert Systems with Applications, 34(3), 2210-2220. https://doi.org/10. 1016/j.eswa.2007.02.042

Cheng, S. R., Hsu, B. M., \& Shu, M. H. (2007). Fuzzy testing and selecting better processes performance. Industrial Management and Data Systems, 107(6), 862-881. https://doi.org/10.1108/02635570710758761

Chin, W. C., Lee, M. C., \& Yap, G. L. C. (2016). Modelling financial market volatility using asymmetric-skewedARFIMAX and -HARX models. Inzinerine Ekonomika - Engineering Economics, 27(4), 373-381. http://dx.doi.org/10.5755/j01.ee.27.4.13927

Curt, C., Hossenlopp, J., \& Trystram, G. (2007). Control of food batch processes based on human knowledge. Journal of Food Engineering, 79(4), 1221-1232. https://doi.org/10.1016/j.jfoodeng.2006.04.052

Dehghanbaghi, M., Hosseininasab, H., \& Sadeghieh, A. (2016). A hybrid approach to support recovery strategies (A case study). Journal of Cleaner Production, 113, 717-729. https://doi.org/10.1016/j.jclepro.2015.11.064

Deng, Q. W., Liao, H.-L., Xu, B. W., Liu, X. H. (2017). The resource benefits evaluation model on remanufacturing processes of end-of-life construction machinery under the uncertainty in recycling price. Sustainability, 9(2), 256. https://doi.org/10.3390/su9020256

Drejeriene, E., \& Drejeris, R. (2017). Systematic approach to a new service ideas conceptualisation: quantitative decision making. Inzinerine Ekonomika-Engineering Economics, 28(3), 323-333. https://doi.org/10.5755/j01.ee.28.3.14752

Ervural, B. C., Ervural, B., \& Kabak, O. (2016). A Group Decision Making Approach for the Evaluation of Flexible Manufacturing Systems. IFAC-PapersOnLine, 49(12), 1329-1334. https://doi.org/10.1016/j.ifacol.2016.07.708

Feng, C. X. J., Gowrisankar, A. C., Smith, A. E., \& Yu, Z. G. S. (2006). Practical guidelines for developing BP neural network models of measurement uncertainty data. Journal of Manufacturing Systems, 25(4), 239-250. https://doi.org/10.1016/S0278-6125(08)00006-X

Fernandez, A. J. (2017). Economic lot sampling inspection from defect counts with minimum conditional value-at-risk. European Journal of Operational Research, 258(2), 573-580. https://doi.org/10.1016/j.ejor.2016.10.042

Garsviene, L., \& Cibulskiene, D. (2017). Evaluation of the factors determining risk of growing current account deficit to the country in the context of economic growth. Inzinerine Ekonomika-Engineering Economics, 28(1), 4-14. http://dx.doi.org/10.5755/j01.ee.28.1.10961

Gray, J. V., Roth, A. V., \& Tomlin, B. (2009). The influence of cost and quality priorities on the propensity to outsource production. Decision Sciences, 40(4), 697-726. https://doi.org/10.1111/j.1540-5915.2009.00248.x

Hahn, G.J., Sens, T., Decouttere, C., \& Vandaele, N.J. (2016). A multi-criteria approach to robust outsourcing decisionmaking in stochastic manufacturing systems. Computers and Industrial Engineering, 98, 275-288. https://doi.org/10.10 16/j.cie.2016.05.032

Hejazi, T. H., Seyyed-Esfahani, M., \& Antony, J. (2017). A new methodology based on multistage stochastic programming for quality chain design problem. International Journal of Industrial Engineering: Theory Applications and Practice, 24(1), 12-31.

Jarmai, K. (2007). Single- and multiobjective optimization of a welded stringer-stiffened cylindrical shell. Periodica Polytechnica Civil Engineering, 51(2), https://doi.org/11-18. 10.3311/pp.ci.2007-2.03

Jiang, Y., Seidmann, A. (2014). Capacity planning and performance contracting for service facilities. Decision Support Systems, 58(1), 31-42. https://doi.org/10.1016/j.dss.2013.01.010

Jin, Y., Ryan, J. K., \& Yund, W. (2014).Two stage procurement processes with competitive suppliers and uncertain supplier quality. IEEE Transactions on Engineering Management, 61(1), 147-158. https://doi.org/10.1109/TEM. 2013.2266276

Kaur, M., Singh, K., Ahuja, I. S., \& Singh, P. (2015). Justification of synergistic implementation of TQM-TPM paradigms using analytical hierarchy process. International Journal of Process Management and Benchmarking, 5(1), 1-18. https://doi.org/10.1504/IJPMB.2015.066028 
Kondoh, S., \& Salmi, T. (2011). Strategic decision making method for sharing resources among multiple manufacturing/remanufacturing systems. Journal of Remanufacturing, 1(1), 5. https://doi.org/10.1186/2210-4690-1-5

Korponai, J., Toth, A. B., \& Illes, B. (2017). The Effect of the Safety Stock on the Occurrence Probability of the Stock Shortage. Management and Production Engineering Review, 8(1), 69-77. https://doi.org/10.1515/mper-2017-0008

Kucharska, E., Grobler-Debska, K., \& Raczka, K. (2017). Algebraic-logical meta-model based approach for scheduling manufacturing problem with defects removal. Advances in Mechanical Engineering, 9(4), 1-18. https://doi.org/10. 1177/1687814017692291

Kuhn, J. (2006). Evolution of a worldwide production network. Journal of Manufacturing Technology Management, 17(8), 1099-1116. https://doi.org/10.1108/17410380610707401

Kundrak, J., Varga, G., Deszpoth, I., \& Molnar, V. (2013). Some aspects of the hard machining of bore holes. Applied Mechanics and Materials, 309, 126-132. https://doi.org/10.4028/www.scientific.net/AMM.309.126

Kuntiyawichai, K., \& Limkatanyu, S. (2006). State of the art in quality assurance issues of structures with particular emphasis on strength degradation. Songklanakarin Journal of Science and Technology, 28(6), 1289-1304.

Lage, M., \& Filho, G. (2010). Variations of the Kanban system: Literature review and classification. International Journal of Production Economics, 125(1), 13-21. https://doi.org/10.1016/j.ijpe.2010.01.009

Loftus, P., \& Giudice, S. (2014). Relevance of methods and standards for the assessment of measurement system performance in a High-Value Manufacturing Industry. Metrologia, 51(4), 219-227. https://doi.org/10.1088/0026$1394 / 51 / 4 / \mathrm{S} 219$

Mehrez, A., Muzumdar, M., Acar, W., \& Weinroth, G. (1995). A Petri Net model view of decision making: an operational management analysis. Omega, 23(1), 63-78. https://doi.org/10.1016/0305-0483(94)00049-G

Mohammadi, M., Siadat, A., Dantan, J. Y., \& Tavakkoli-Moghaddam, R. (2015). Mathematical modelling of a robust inspection process plan: Taguchi and Monte Carlo methods. International Journal of Production Research, 53(7), 2202-2224. https://doi.org/10.1080/00207543.2014.980460

Molnar, V. (2017). Indirect impacts of drastic scrap rate reduction on costs of production process in precision machining. Solid State Phenomena, 261, 487-494. http://doi.org/10.4028/www.scientific.net/SSP.261.487

Moradi-Aliabadi, M., \& Huang, Y. (2016). Multistage optimization for chemical process sustainability enhancement under uncertainty. ACS Sustainable Chemistry and Engineering, 4(11), 6133-6143. https://doi.org/10.1021/ acssuschemeng.6b01601

Mourtzis, D., Doukas, M., \& Psarommatis, F. (2015). A toolbox for the design, planning and operation of manufacturing networks in a mass customisation environment. Journal of Manufacturing Systems, 36, 274-286. https://doi.org/10.1016/ j.jmsy.2014.06.004

Noori, S., Feylizadeh, M. R., Bagherpour, M., Zorriassatine, F., \& Parkin, R. M. (2008). Optimization of material requirement planning by fuzzy multi-objective linear programming. Proceedings of the Institution of Mechanical Engineers, Part B: Journal of Engineering Manufacture, 222(7), 887-900. https://doi.org/10.1243/09544054JEM1014

Orji, I. J., \& Wei, S. (2014). A decision support tool for sustainable supplier selection in manufacturing firms. Journal of Industrial Engineering and Management, 7(5), 1293-1315. https://doi.org/10.3926/jiem.1203

Ouisse, M., \& Cogan, S. (2010). Robust design of spot welds in automotive structures: A decision-making methodology. Mechanical Systems and Signal Processing, 24(4), 1172-1190. https://doi.org/10.1016/j.ymssp.2009.09.012

Pochampally, K. K., \& Gupta, S. M. (2005). Strategic planning of a reverse supply chain network. International Journal of Integrated Supply Management, 1(4), 421-441.

Sayyadi Tooranloo, H., \& Ayatollah, A. S. (2016). A model for failure mode and effects analysis based on intuitionistic fuzzy approach. Applied Soft Computing Journal, 49, 238-247. https://doi.org/10.1016/j.asoc.2016.07.047

Samantra, C., Sahu, N. K., Datta, S., \& Mahapatra, S. S. (2013). Decision-making in selecting reverse logistics alternative using interval-valued fuzzy sets combined with VIKOR approach. International Journal of Services and Operations Management, 14(2), 175-196. https://doi.org/10.1504/IJSOM.2013.051828

Sarina, Zhang, S., \& Qiu, L. (2012). Quality house model with dependence and feedback for manufacturing equipment process and performance requirements conversion. Jixie Gongcheng Xuebao/Journal of Mechanical Engineering, 48(15), 164-172. https://doi.org/10.3901/JME.2012.15.164

Shukla, R., Goyal, S., Singh, A. K., Panchal, J. H., Allen, J. K., \& Mistree, F. (2015). Design Exploration for Determining the Set Points of Continuous Casting Operation: An Industrial Application. Journal of Manufacturing Science and Engineering, Transactions of the ASME, 137(3), 034503. https://doi.org/10.1115/1.4029786

Silingiene, V., \& Skeriene, S. (2016). Links between the Spiritual Intelligence of the Leader and an Organization's Service Quality: a Theoretical Approach. Inzinerine Ekonomika - Engineering Economics, 27(1), 56-65. http://dx.doi.org/10. 57 55/j01.ee.27.1.8863 
Singh, K., \& Ahuja, I. S. (2012). Justification of TQM-TPM implementations in manufacturing organisations using analytical hierarchy process: A decision-making approach under uncertainty. International Journal of Productivity and Quality Management, 10(1), 69-84. https://doi.org/10.1504/IJPQM.2012.047942

Snieska, V., Daunoriene, A., \& Zekeviciene, A. (2013). Hidden Costs in the Evaluation of Quality Failure Costs. Inzinerine Ekonomika - Engineering Economics, 24(3), 176-186. http://dx.doi.org/10.5755/j01.ee.24.3.1186

Su, H. C., \& Linderman, K. (2016). An Empirical Investigation in Sustaining High-Quality Performance. Decision Sciences, 47(5), 787-819. https://doi.org/10.1111/deci.12210

Summers, G. J., \& Scherpereel, C. M. (2008). Decision making in product development: Are you outside-in or inside-out? Management Decision, 46(9), 1299-1312. https://doi.org/10.1108/00251740810911957

Tang, J. W., \& Hsu, T. H. (2015). A fuzzy preference relations model for evaluating key supplier relationships in TFTLCD TV panel manufacturing industry. Management Decision, 53(8), 1858-1882. https://doi.org/10.1108/MD-122014-0691

Tseng, M. L., \& Lin, Y. H. (2008). Selection of competitive advantages in TQM implementation using fuzzy AHP and sensitivity analysis. Asia Pacific Management Review, 13(3), 583-599.

Villeta, M., Rubio, E. M., Valencia, J. L., \& Sebastian, M. A. (2012). Integrating the continuous improvement of measurement systems into the statistical quality control of manufacturing processes: A novel link. CIRP Annals Manufacturing Technology, 61(1), 507-510. https://doi.org/10.1016/j.cirp.2012.03.017

Winston, W. L. (1994). Operations Research. Applications and Algorithms. Duxbury Press

Wudhikarn, R., Chakpitak, N., \& Neubert, G. (2015). Use of an analytic network process and monte carlo analysis in new product formula selection decisions. Asia-Pacific Journal of Operational Research, 32(2), 1550007. https://doi.org/10.1142/S0217595915500074

Xu, W., Zhang, Q., \& Ma, J. (2013). The relationship among customer demand, competitive strategy and manufacturing system functional objectives. Journal of Industrial Engineering and Management, 6(4), 1238-1254. https://doi.org/10. 3926/jiem.802

Yan, H. B., Ma, T., \& Huynh, V. N. (2014). Coping with Group Behaviors in Uncertain Quality Function Deployment. Decision Sciences, 45(6), 1025-1052. https://doi.org/10.1111/deci.12104

Yao, M. A., Higgs, T. G., Cullen, M. J., Stewart, S., \& Brady, T. A. (2010). Comparative assessment of life cycle assessment methods used for personal computers. Environmental Science and Technology, 44(19), 7335-7346. https://doi.org/10. 1021/es903297k

Yu, J., \& Ma, S. (2013). Impact of decision sequence of pricing and quality investment in decentralized assembly system. Journal of Manufacturing Systems, 32(4), 664-679. https://doi.org/10.1016/j.jmsy.2013.02.004

Zhang, T., Qu, T., Huang, G. Q., Chen, X., \& Wang, Z. (2016). Sizing, pricing and common replenishment in a headquartermanaged centralized distribution center. Industrial Management and Data Systems, 116(6), 1086-1104. https://doi.org/10.1108/IMDS-08-2015-0343

Zhao, Z., Ball, M. O., \& Kotake, M. (2005). Optimization-based available-to-promise with multi-stage resource availability. Annals of Operations Research, 135(1), 65-85. https://doi.org/10.1007/s10479-005-6235-7

The article has been reviewed.

Received in October, 2017; accepted in February, 2019. 